\title{
Article \\ The Antidiabetic Effect of Grape Pomace Polysaccharide-Polyphenol Complexes
}

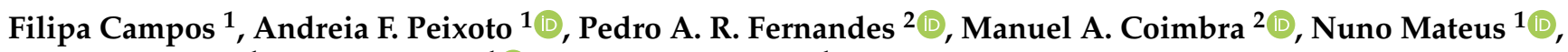 \\ Victor de Freitas ${ }^{1}$, Iva Fernandes ${ }^{1}\left(\mathbb{D}\right.$ and Ana Fernandes ${ }^{1, *}$ \\ 1 REQUIMTE-Laboratório Associado Para a Química Verde, Departamento de Química e Bioquímica, \\ Faculdade de Ciências, Universidade do Porto, Rua do Campo Alegre 687, 4169-007 Porto, Portugal; \\ filipasc96@hotmail.com (F.C.); andreia.peixoto@fc.up.pt (A.F.P.); nbmateus@fc.up.pt (N.M.); \\ vfreitas@fc.up.pt (V.d.F.); iva.fernandes@fc.up.pt (I.F.) \\ 2 LAQV/REQUIMTE, REQUIMTE-Laboratório Associado Para a Química Verde, Departmento de Química, \\ Universidade de Aveiro, Campus Universitário de Santiago, 3810-193 Aveiro, Portugal; \\ pedroantonio@ua.pt (P.A.R.F.); mac@ua.pt (M.A.C.) \\ * Correspondence: ana.fernandes@fc.up.pt; Tel.: +35-122-040-2596
}

Citation: Campos, F.; Peixoto, A.F.; Fernandes, P.A.R.; Coimbra, M.A.; Mateus, N.; de Freitas, V.; Fernandes, I.; Fernandes, A. The Antidiabetic Effect of Grape Pomace PolysaccharidePolyphenol Complexes. Nutrients 2021, 13, 4495. https://doi.org/ $10.3390 /$ nu13124495

Academic Editor: Roberto Cangem

Received: 4 November 2021

Accepted: 10 December 2021

Published: 15 December 2021

Publisher's Note: MDPI stays neutral with regard to jurisdictional claims in published maps and institutional affiliations.

Copyright: (c) 2021 by the authors. Licensee MDPI, Basel, Switzerland. This article is an open access article distributed under the terms and conditions of the Creative Commons Attribution (CC BY) license (https:// creativecommons.org/licenses/by/ $4.0 /)$.

\begin{abstract}
Type 2 diabetes mellitus (T2DM) is one of the most prevalent chronic metabolic diseases of the 21st century. Nevertheless, its prevalence might be attenuated by taking advantage of bioactive compounds commonly found in fruits and vegetables. This work is focused on the recovery of polyphenols and polysaccharide-polyphenol conjugates from grape pomace for T2DM management and prevention. Bioactives were extracted by solid-liquid extraction and by pressurized hot water extraction (PHWE). Polyphenolic fraction recovered by PHWE showed the highest value for total phenolic content (427 $\mu$ g GAE.mg ${ }^{-1}$ ), mainly anthocyanins and proanthocyanidins, and higher antioxidant activity compared to the fraction recovered by solid-liquid extraction. Polysaccharidepolyphenol conjugates comprehended pectic polysaccharides to which approximately $108 \mu \mathrm{g}$ GAE of phenolic compounds (per mg fraction) were estimated to be bound. Polyphenols and polysaccharidepolyphenol conjugates exhibited distinct antidiabetic effects, depending on the extraction methodologies employed. Extracts were particularly relevant in the inhibition of a-glucosidase activity, with free polyphenols showing an $\mathrm{IC}_{50}$ of $0.47 \mu \mathrm{g} \cdot \mathrm{mL}^{-1}$ while conjugates showed an $\mathrm{IC}_{50}$ of 2.7, 4.0 and $5.2 \mu \mathrm{g} . \mathrm{mL}^{-1}$ (solid-liquid extraction, PHWE at 95 and $120^{\circ} \mathrm{C}$, respectively). Antiglycation effect was more pronounced for free polyphenols recovered by PHWE, while the attenuation of glucose uptake by Caco- 2 monolayers was more efficient for conjugates obtained by PHWE. The antidiabetic effect of grape pomace bioactives opens new opportunities for the exploitation of these agri-food wastes in food nutrition, the next step towards reaching a circular economy in grape products.
\end{abstract}

Keywords: anthocyanins; diabetes mellitus; polyphenols; polysaccharides; polysaccharide-polyphenol conjugates; pressurized hot water extraction

\section{Introduction}

The rapid progress of civilization and lifestyle changes has created factors with adverse effects for the health of society. This has led to increased morbidity from several chronic noncommunicable diseases. Diabetes mellitus (DM) is a serious multifactorial metabolic disorder which has great impact on health and life expectancy of affected individuals. It is characterized by high sugar concentrations in the blood, due to impaired insulin secretion, resistance to peripheral actions of insulin, or both [1]. In the past years, research has been driven into the search of functional bioactive compounds present in plants, namely polyphenols, for type $2 \mathrm{DM}$ (T2DM) prevention and management [2,3]. Indeed, due to their antioxidant properties, polyphenols have gained significant importance in the fields of food nutrition and health. For instance, the role of polyphenols on the inhibition of pro-inflammatory transcription factors or the use of polyphenols as attenuating agents of 
immune reactions to food by interacting with specific allergen proteins, emphasize the concept of polyphenols as functional ingredients with preventive and therapeutic potential in noncommunicable diseases [4].

In plant-derived foods, polyphenols can be found in free and bound form. While free polyphenols are easily extracted with polar aqueous/organic solvents, bound or non-extractable polyphenols remain insoluble in the solvent used for the extraction, as they are retained in the plant matrix. Non-extractable polyphenols include both high molecular weight polymeric polyphenols (e.g., condensed and hydrolyzable tannins) and low molecular weight phenolic compounds such as phenolic acids and subclasses of some flavonoids, which are associated with cell wall components such as polysaccharides and proteins [5-7]. The formation of polysaccharide-polyphenol conjugates may be mediated by several non-covalent interactions such as hydrogen bonding, hydrophobic interaction, or encapsulation within hydrophobic pockets [8,9]. Additionally, polysaccharides may establish covalent bonds with polyphenols as a result of biosynthetic procedures [10,11] or by means of polyphenol oxidation reactions during fruit processing [12].

Polysaccharide-polyphenol conjugates have attracted considerable attention from the scientific community, as they may combine the antioxidant activity of polyphenolic compounds and the physiological effects of polysaccharides [13]. Similar to polyphenols, the consumption of polysaccharides is associated with human health benefits, such as the improvement in gastrointestinal health and the treatment of some cardiovascular diseases and some types of cancer [14]. A reduction in hyperlipidemia, hypertension, modification of the glucose tolerance and insulin response, and increased satiety are other physiological effects associated with the consumption of polysaccharides [15]. Thus, polysaccharidepolyphenol conjugates are certain to have a bright prospect in the fields of functional foods.

Besides fruit and vegetables, agri-food by-products may be a relevant source of bioactive compounds [5]. Grape pomace (Vitis vinifera L.), one of the main wastes from the wine industry, can be regarded as an excellent and affordable source of polyphenols, mainly anthocyanins (malvidin-3-O-glucoside, peonidin-3-O-glucoside, acylated derivatives), flavan3-ols (epicatechin-3-O-gallate and epicatechin, catechins), flavonols (quercetin, myricetin), phenolic acids (gallic acid, syringic acid) and stilbenes (resveratrol) [16]. However, studies regarding the macromolecular fraction of grape pomace are scarce, especially related to polysaccharide-polyphenol conjugates extraction and structural characterization. Concerning polyphenols-wine polymeric material interaction, Gonçalves et al. [17] suggested that they may occur in different energetic layers, ruled by non-covalent interactions and by covalent linkages. Therefore, the research on polysaccharides-polyphenols conjugates, their physicochemical characteristics and bioactivities is crucial for the development of dietary supplements and functional foods.

The recovery of free polyphenols and polysaccharide-polyphenol conjugates can be a solution to mitigate grape pomace as an agri-food disposable. In this work, it was intended to recover free polyphenols and polysaccharide-polyphenol conjugates through solid-liquid extraction and under pressurized hot water conditions. The use of water under these conditions provides advantages over conventional extraction methods, such as being sustainable, faster, and more efficient [18-20]. Free polyphenols are well recognized as potent antioxidants and inhibitors of carbohydrate metabolizing enzymes. In this sense, polyphenols bound to polysaccharides may also play a fundamental role as antidiabetic agents. The potential application of these bioactives was evaluated through the modulation of: (i) the activity of carbohydrate-metabolizing enzymes, (ii) the formation of advanced glycation end products (AGEs) and (iii) the intestinal glucose uptake.

\section{Materials and Methods}

\subsection{Plant Material}

Polyphenols and polysaccharide-polyphenol conjugates were extracted from destemmed red grape pomace from Portuguese varieties (Vitis vinifera L. cv.), kindly provided by a local winemaker (cultivars located in Chaves, Portugal). Red grape pomace was collected 
after the last alcoholic fermentation step (7 days) in October 2020 , frozen at $-20{ }^{\circ} \mathrm{C}$ and freeze-dried prior to their use. Prior to the extraction procedure, most of the grape seeds were manually removed.

\subsection{Extraction Procedures}

Polyphenol's extraction from the grape pomace was performed for $2 \mathrm{~h}$ at room temperature using acidified 50\% hydroethanolic solutions ( $\mathrm{pH} 2.3$ with citric acid at $73 \% w / w)$ at a ratio of 1:10. The obtained suspension was then filtered on a cloth filter, followed by centrifugation at 10,000 rpm (Dynamica Velocity 14R Refrigerated Centrifuge, Dynamica Scientific Ltd.; Livingston, United Kingdom) for $10 \mathrm{~min}$ at room temperature. Organic solvent was removed by evaporation and the aqueous extract was purified by C-18 reversed phase silica gel chromatography using a Büchner funnel and a vacuum filtration system. Briefly, the extract was applied on the top of the gel. Elution was first made with distilled water to remove inorganic salts and small sugars and then with methanol to recover free polyphenols. This fraction was evaporated and freeze dried, giving a free polyphenolic fraction (FP).

Polysaccharide-polyphenol conjugates were obtained by alkaline and pressurized hot water extractions following the general procedure described for medicinal and edible plants [21,22]. Alkaline extraction was performed by suspending $5 \mathrm{~g}$ of grape pomace in $50 \mathrm{~mL}$ of $0.1 \mathrm{M} \mathrm{NaOH}$ for $24 \mathrm{~h}$ at room temperature, without any pre-treatment [23]. Thereafter the mixture was extracted at $96{ }^{\circ} \mathrm{C}$ under reflux for $6 \mathrm{~h}$. The supernatant was then recovered by centrifugation at $10,000 \mathrm{rpm}$ for $10 \mathrm{~min}$ at room temperature (Dynamica Velocity 14R Refrigerated Centrifuge, Dynamica Scientific Ltd.; Livingston, United Kingdom) and neutralized with $\mathrm{HCl} 0.1 \mathrm{M}$, giving a crude extract. The isolated crude extract was purified according to Pawlaczyk-Graja and co-workers [24]. First, the crude extract was dissolved in $250 \mathrm{~mL}$ of distilled water and extracted twice with $n$ hexane $(1: 1 \mathrm{v} / \mathrm{v})$ for $6 \mathrm{~h}$ at $69^{\circ} \mathrm{C}$ and with diethyl ether $(1: 1 \mathrm{v} / \mathrm{v})$ for $6 \mathrm{~h}$ at $34^{\circ} \mathrm{C}$ to remove hydrophobic compounds. The aqueous fraction was evaporated to a paste-like form and treated with $100 \mathrm{~mL}$ of methanol at room temperature for $24 \mathrm{~h}$ to eliminate lowmolecular-weight phenolic compounds [25]. The formed precipitates were recovered by centrifugation at 10,000 rpm for $10 \mathrm{~min}$ (Dynamica Velocity 14R Refrigerated Centrifuge, Dynamica Scientific Ltd.; Livingston, United Kingdom) and dried overnight at room temperature. The dried material was redissolved in $150 \mathrm{~mL}$ in deionized water, dialyzed for $48 \mathrm{~h}$ with at least 6 water renewal, (Spectra/Por $\left.{ }^{\circledR}, 12-14 \mathrm{MWCO}\right)$ and freeze dried, giving an alkaline extract (AE).

PHWE was conducted on a Parr Series 4560 Reactor (Parr Instrument Company, Moline, IL, USA), connected to the Parr 4848 Reactor Controller. The extractions were performed using $10 \mathrm{~g}$ of grape pomace and $100 \mathrm{~mL}$ of distilled water (acidified at $\mathrm{pH} 2.3$ with citric acid at $73 \% \mathrm{w} / \mathrm{w}$ ) at $120{ }^{\circ} \mathrm{C}$ for $30 \mathrm{~min}$. To limit the thermal degradation of polyphenols, a lower extraction temperature $\left(95^{\circ} \mathrm{C}\right)$ and pomace:water ratio was also tested (1:30) for $30 \mathrm{~min}$ [26]. Both extractions were performed under inert atmosphere at 5.5 Bar and at $145 \mathrm{rpm}$. After extraction, the system was cooled down and the extracts were filtered under vacuum, through a glass fiber filter (Whatman GF/C) and centrifuged at 10,000 rpm for $10 \mathrm{~min}$ at room temperature (Dynamica Velocity 14R Refrigerated Centrifuge, Dynamica Scientific Ltd.; Livingston, United Kingdom). The extracts were evaporated to a paste-like form and treated as previously described, giving two PHWE extracts, PHWE-95 and PHWE-120.

For the PHWE at $95^{\circ} \mathrm{C}$, the supernatant recovered after precipitation with methanol, was treated to isolate free polyphenols. Methanolic extract was purified by C-18 reversed phase silica gel chromatography as previously described. This fraction was evaporated and freeze dried, giving a free polyphenolic fraction (FP-95). 


\subsection{Physicochemical Characterization}

\subsubsection{Determination of Polyphenols, Proteins and Sugar Content}

Polyphenolic content of each fraction (FP, FP-95, AE, PHWE-95 and PHWE-120,) was determined through the Folin-Ciocalteu assay [27]. Results were expressed as $\mu \mathrm{g}$ gallic acid equivalents (GAE). $\mathrm{mg}^{-1}$ dry weight in each fraction.

Protein content was determined using a dye binding assay (Bradford Protein Assay Kit-Thermo Scientific, Waltham, MA, USA), using BSA as standard [28]. Results were expressed as $\mu \mathrm{g}$ BSA equivalents $\mathrm{mg}^{-1}$.dry weight in each fraction.

Sugar content in FP and FP-95 extracts was determined by GC-MS after derivatization [29]. Derivatization with hexamethyldisilazane (HMDS) was applied for the trimethylslylation (TMS) of polar functional groups. The procedure was as follows: (a) $600 \mu \mathrm{L}$ of HMDS:acetonitrile mixture $(1: 1 v / v)$ was added as a silylation agent to $20 \mu \mathrm{L}$ of aqueous solution for the derivatization of easily silylable functional groups (e.g., hydroxyl in glucose), $2 \mu \mathrm{L}$ of trifluoroacetic acid was added as a catalyst and the sample was heated to $50{ }^{\circ} \mathrm{C}$ for $30 \mathrm{~min}$. The vial was left open during this process to ensure the escape of the ammonia gas produced in the reaction. Subsequently, (b) in the second step, $400 \mu \mathrm{L}$ of pure HMDS was added and the mixture was heated to $80^{\circ} \mathrm{C}$ for $30 \mathrm{~min}$ in a closed vial. After cooling to laboratory temperature $1 \mu \mathrm{L}$ of the resulting solution was injected into the GC-MS/MS system. Derivatization was performed in triplicate. The GC-MS/MS analyses were carried out with a Trace 1300 gas chromatograph equipped with a split-splitless injector, an autosampler 1310 Thermo Scientific and a ISQ Single quadrupole MS (Thermo Fisher, Austin, TX, USA). A total of $1 \mu \mathrm{L}$ of the sample was injected into the injector operating in splitless mode. The temperatures of the injector and the MS-transfer line were $250{ }^{\circ} \mathrm{C}$ and $300{ }^{\circ} \mathrm{C}$, respectively. Compounds were separated on a $30 \mathrm{~m} \times 0.25 \mathrm{~mm}$ (i.d.) $\times 0.25 \mu \mathrm{m}$ DB-17 capillary column (Agilent Technologies, CA, USA) operating at constant helium flow of $1.5 \mathrm{~mL} \cdot \mathrm{min}^{-1}$. The column temperature was initially set to $110^{\circ} \mathrm{C}$, held for $5 \mathrm{~min}$, increasing then at a rate of $6^{\circ} \mathrm{C}$. $\mathrm{min}^{-1}$ to $300^{\circ} \mathrm{C}$ and held for $5 \mathrm{~min}$. Measurements were performed in SCAN mode with $\mathrm{m} / \mathrm{z}$ range set to $40-1100$. The MS conditions were as follows: ion source temperature $280{ }^{\circ} \mathrm{C}$ and electron energy $70 \mathrm{eV}$, using glucose as standard for the calibration curve. Selected ion monitoring (SIM) conditions were used for the glucose, selecting the $m / z 204$. Results were expressed as $\mu \mathrm{g}$ glucose equivalents $\mathrm{mg}^{-1}$.dry weight in each fraction.

\subsubsection{Carbohydrate Analysis}

The carbohydrate compositions of AE, PHWE-95 and PHWE-120 extracts were determined by neutral sugars and uronic acid quantification. Neutral sugars were quantified by GC-FID after acid hydrolysis and derivatization to alditol acetates, using deoxyglucose as internal standard [30]. Uronic acids (UA) were quantified by the 3-phenylphenol colorimetric method [31] using D-galacturonic acid as a standard. Results were expressed as mg sugar. ${ }^{-1}$ dry sample.

\subsubsection{Polymeric Colour Index}

Polymeric colour index was determined by measuring the absorbances of FP and FP-95 extract solutions that had been treated with sodium bisulfite (20\%) compared to non-treated samples [32]. $2.8 \mathrm{~mL}$ of diluted samples (in distilled water) were transferred to each of two cuvettes, and $0.2 \mathrm{~mL}$ of bisulfite solution or distilled water was added. The samples were left to equilibrate in the dark for $15 \mathrm{~min}$. The absorbance of each sample was measured at $420 \mathrm{~nm}, \lambda_{\max }$ and $700 \mathrm{~nm}$ (to correct for haze) on a UV-Visible spectrophotometer (Thermo Scientific Evolution Array, Waltham, MA, USA). The colour density of the control sample (treated with water) and polymeric colour (bisulfite bleached sample) was calculated as follows:

$$
\begin{gathered}
\text { Colour Density }=\left[\left(\mathrm{A}_{420 \mathrm{~nm}}-\mathrm{A} 700 \mathrm{~nm}\right)+(\mathrm{A} \lambda \max -\mathrm{A} 700 \mathrm{~nm})\right] \times \mathrm{DF} \\
\text { Polymeric color }=\left[\left(\mathrm{A}_{420 \mathrm{~nm}}-\mathrm{A}_{700 \mathrm{~nm}}\right)+\left(\mathrm{A}_{\lambda \max }-\mathrm{A}_{700 \mathrm{~nm}}\right)\right] \times \mathrm{DF}
\end{gathered}
$$


where DF is the dilution factor.

The percentage of polymeric colour was calculated using the formula:

Percentage polymeric color $=($ polymeric color $/$ color density $) \times 100$

\subsubsection{Reverse Phase Liquid Chromatography Analysis of Polyphenols}

The anthocyanins content in FP and FP-95 extracts was analyzed by UPLC-DAD (Dionex Ultimate 3000, Thermo Scientific, Waltham, MA, USA) on a C-18 gel column (250 $\mathrm{mm} \times 4.6 \mathrm{~mm}$ i.d.; $5 \mu \mathrm{m}$, Thermo Scientific), using $\mathrm{HCOOH} / \mathrm{H}_{2} \mathrm{O}(10 / 90, v / v)$ and $\mathrm{HCOOH} / \mathrm{CH}_{3} \mathrm{CN} / \mathrm{H}_{2} \mathrm{O}(10 / 30 / 60, v / v)$ as solvents [33]. Results were expressed as $\mu \mathrm{g}$ malvidin-3-O-glucoside equivalents. $\mathrm{mg}^{-1}$ dry weight.

To analyze the content of non-anthocyanic compounds (low molecular weight polyphenols, proanthocyanidins and flavonols), aqueous extracts were mixed with ethyl acetate and acetonitrile $2 / 2 / 1(v / v / v)$ in microtubes, placed in a shaker for $10 \mathrm{~s}$ and centrifuged for $5 \mathrm{~min}$ at $8000 \mathrm{rpm}$. After centrifugation and phase separation, liquid-liquid extraction was repeated for the aqueous phase. Organic phases were combined, and the organic solvent evaporated in a speed vacuum [34]. The obtained fraction was then re-suspended in water/methanol $(1 / 1 ; v / v)$ and analyzed by UPLC-DAD, using $\mathrm{CH}_{3} \mathrm{COOH} / \mathrm{H}_{2} \mathrm{O}(1 / 99, v / v)$ and $\mathrm{CH}_{3} \mathrm{COOH} / \mathrm{CH}_{3} \mathrm{CN} / \mathrm{H}_{2} \mathrm{O}(1 / 20 / 79, v / v)$ as solvents [35]. Results were expressed as $\mu \mathrm{g}$ GAE.mg ${ }^{-1}$ dry weight.

\subsubsection{High Performance Liquid Chromatography-Mass Spectrometry} (HPLC-DAD/ESI-MS) Analysis of Polyphenols

The identification of polyphenols was performed by LC-DAD/ESI-MS [35-37]. A Finnigan Surveyor series liquid chromatograph equipped with a Thermo Finnigan (Hypersil Gold) C-18 reversed-phase column $(150 \mathrm{~mm} \times 4.6 \mathrm{~mm}$, i.d.; $5 \mu \mathrm{m}$, Thermo Scientific) thermostatted at $25^{\circ} \mathrm{C}$ was used. Detection was carried out between 200 and $700 \mathrm{~nm}$ using a Finnigan Surveyor PDA Plus detector. Mass detection was made on a Finnigan LCQ DECA XP MAX (Finnigan Corp., San Jose, CA, USA) quadrupole ion trap equipped with an atmospheric pressure ionization (API) source using an electrospray ionization (ESI) source. The vaporizer and capillary voltages were $5 \mathrm{kV}$ and $4 \mathrm{~V}$, respectively. The capillary temperature was set at $325^{\circ} \mathrm{C}$. Nitrogen was used as both sheath and auxiliary gas at flow rates of 80 and 30, respectively (in arbitrary units). Spectra were recorded in the negativeor positive-ion mode between $m / z 120$ and 2000. The mass spectrometer was programmed to do a series of three scans: a full mass, a zoom scan of the most intense ion in the first scan, and an MS-MS of the most intense ion using relative collision energies of 30 and $60 \mathrm{~V}$.

To identify the polyphenolic compounds, present in the conjugate fractions, these fractions were hydrolyzed with an acidic solvent [38-40]. Briefly, $20 \mathrm{mg}$ of conjugates were dissolved in $1.5 \mathrm{~mL}$ of distilled water and hydrolyzed by adding $0.5 \mathrm{~mL}$ of $\mathrm{HCl}$ $(37 \% w / w)$. The mixture was incubated in thermoblock at $85^{\circ} \mathrm{C}$ for $30 \mathrm{~min}$. The aqueous fraction was extracted with $1.5 \mathrm{~mL}$ of diethyl ether:ethyl acetate $(1: 1 \mathrm{v} / \mathrm{v})$. The mixture was vortexed for $45 \mathrm{~s}$ and centrifuged for $10 \mathrm{~min}$ at 10,000 rpm. This extraction was performed three times. The organic layers containing phenolic acids liberated from acid hydrolysis were combined and evaporated to dryness on a speed vacuum (CentriVac Concentrator Labconco, Kansas City, MO, USA) while the aqueous layer was freeze-dried. Residues were re-dissolved in $0.100 \mathrm{~mL}$ water and samples were analyzed by reversed-phase UPLC-DAD and LC-DAD/ESI-MS as described in the Section 2.3.4.

\subsection{Antioxidant Activity}

Ferric Reducing Antioxidant Power (FRAP) and antiradical activity, using 2,2'-diphenyl1-picrylhydrazyl radical (DPPH) assays, were performed according to the literature [41,42] with some modifications. FRAP solution consisted of a mixture of $1 \mathrm{~mL}$ of TPTZ, $1 \mathrm{~mL}$ of iron (III) chloride and $10 \mathrm{~mL}$ of acetate buffer $\left(300 \mathrm{mmol}^{-1} \mathrm{~L}^{-1}, \mathrm{pH} 3.6\right)$, placed in the oven at $37^{\circ} \mathrm{C}$ for $10 \mathrm{~min} ; 10 \mathrm{~mL}$ of this mixture were diluted in $20 \mathrm{~mL}$ of acetate buffer. In 96-well plates, $270 \mu \mathrm{L}$ of FRAP solution and $30 \mu \mathrm{L}$ of aqueous solution of FP, FP-95, AE, PHWE-95 
and PHWE-120 extracts were mixed, and the absorbance at $593 \mathrm{~nm}$ at $37{ }^{\circ} \mathrm{C}$ was measured at 0 and $4 \mathrm{~min}$ on a plate reader (Biotek Powerwave XS, Santa Clara, CA, USA). Results were expressed as $\mu \mathrm{M}$ Trolox equivalents.

For the DPPH assay, in a 96-well plates, $270 \mu \mathrm{L}$ of DPPH solution (prepared in methanol at a concentration $24.2 \mu \mathrm{g} . \mathrm{mL}^{-1}$ ) was mixed with $30 \mu \mathrm{L}$ of aqueous solution of $\mathrm{FP}$, FP-95, AE, PHWE-95 and PHWE-120 extracts and the absorbance at $515 \mathrm{~nm}$ was recorded every $5 \mathrm{~min}$ for $20 \mathrm{~min}$ on a plate reader (Biotek Powerwave XS, Santa Clara, CA, USA). Results were expressed as $\mu \mathrm{M}$ Trolox equivalents.

\subsection{Antidiabetic Properties}

\subsection{1. $\alpha$-Amylase and a-Glucosidase Inhibitory Assay}

The inhibitory activity of free polyphenols extracts (FP, FP-95) and polysaccharidepolyphenol conjugates (AE, PHWE-95 and PHWE-120) extracts was conducted with pancreatic porcine $\alpha$-amylase (A6255, Sigma Aldrich) and $\alpha$-glucosidase from Saccharomyces cerevisiae (G5003, Sigma Aldrich) using ethylidene-4-nitrophenyl- $\alpha$-D-maltoheptaoside and 4-nitrophenyl- $\alpha$-D-glucopyranoside as enzymes substrates (for $\alpha$-amylase and $\alpha$ glucosidase, respectively). All solutions were prepared in $10 \mathrm{mM}$ phosphate buffer saline solution ( $\mathrm{pH}$ 6.8), except for FP and FP-95 which were prepared in DMSO. First, $\alpha$-amylase (15 U.mg ${ }^{-1}$ ) or a-glucosidase (0.011 U.mg $\left.{ }^{-1}\right)$, alone or with different concentrations of each fraction, was pre-incubated at $37^{\circ} \mathrm{C}$ for $10 \mathrm{~min}$. Then, substrate at $2.5 \mathrm{mM}$ or $0.269 \mathrm{mM}$ (a-amylase and a-glucosidase, respectively) was added to the reaction mixture and the reaction was followed for $50 \mathrm{~min}$ at $405 \mathrm{~nm}$ and $37{ }^{\circ} \mathrm{C}$ on a plate reader (FlexStation 3 Multi-Mode Microplate Reader). Acarbose, an oligosaccharide of microbial origin that is used as inhibitor of carbohydrate digestion for clinical management of T2DM [43], was used as the positive control. Results were expressed as inhibition percentage (Equation (1)) and a non-linear regression dose-response curve was established to calculate $\mathrm{IC}_{50}$ values $\left(\mu \mathrm{g} \cdot \mathrm{mL}^{-1}\right)$ of each fraction.

$$
\text { Inhibition } \%=100-\left(\frac{A_{\text {control }}-A_{\text {sample }}}{A_{\text {control }}} \times 100\right)
$$

\subsubsection{Advanced Glycation End Products (AGEs) Assay}

The AGEs assay uses fluorescence spectroscopy to monitor the inhibitory effect exerted against glycation in the presence or absence of an extract using a reaction model system. The antiglycation activity of polyphenols extracts (FP, FP-95) and polysaccharide-polyphenol conjugates (AE, PHWE-95 and PHWE-120) extracts was determined by BSA-glucose model system [44]. Briefly, $5.0 \mathrm{~mL}$ of reaction mixture (5\% BSA (w/v), $500 \mathrm{mM}$ glucose and $0.1 \%$ sodium azide dissolved in phosphate buffer $(200 \mathrm{mM}, \mathrm{pH} 7.4))$ and polyphenols and conjugates fractions at different concentrations were prepared. Aminoguanidine (AG) was used as the positive control. A blank was prepared without positive control or extracts. The tubes were caped and incubated for 14 days at $37^{\circ} \mathrm{C}$ in the dark in a temperature-controlled incubator. The fluorescence of the glycated solution was determined using a spectrofluorometer at an excitation/emission wavelength of $370 / 440 \mathrm{~nm}$, which is characteristic of advanced glycation end products (AGEs). Results were expressed as inhibition percentage on AGE (Equation (1)) and a non-linear regression dose-response curve was established to calculate the $\mathrm{IC}_{50}$ values $\left(\mu \mathrm{g} \cdot \mathrm{mL}^{-1}\right)$ of each fraction.

\subsubsection{Glucose Uptake Assay}

C2BBe1 (CRL-2102, ATCC) [clone of Caco-2] intestinal cell culture was selected on the basis of morphological homogeneity and exclusive apical villin localization. C2BBe1 cells form a polarized monolayer with an apical brush border morphologically comparable to that of the human colon. Transport study was performed according to the previous published method [45]. C2BBe1 cells were grown at $37{ }^{\circ} \mathrm{C}$ in an atmosphere of $5 \% \mathrm{CO}_{2}$ and $95 \%$ relative humidity and were cultured in Minimum Essential Medium 
Eagle (MEME) that was supplemented with 15\% fetal bovine serum, 25 mM HEPES, $1 \%$ Glutamax, $1 \%$ sodium pyruvate 100 Units. $\mathrm{mL}^{-1}$ penicillin, $100 \mathrm{mg} \cdot \mathrm{mL}^{-1}$ streptomycin, and $0.25 \mathrm{mg} \cdot \mathrm{mL}^{-1}$ amphotericin B (all from Sigma). Culture medium was changed every 2 days, and the cells were passed at the split ratio of 1:4 after full confluence. For transport experiments, C2BBe1 cells were seeded on Transwell inserts at $1.5 \times 10^{5}$ cells.mL $^{-1}$ (polycarbonate membrane, $0.4 \mu \mathrm{m}$ pore size, $24 \mathrm{~mm}$ diameter, Corning, New York, NY, USA). After 21 days, cell monolayers were formed and differentiated. Trans-epithelial electrical resistance values (TEER) in each well were measured using Millicell epithelial voltommeter (Millipore Co., Bedford, MA, USA) with "chopstick" electrodes. Only cell monolayers with TEER values higher than $230 \Omega$ were used for the experiments. Then, the medium was removed, and cells were washed with Hanks buffer (HBSS) (pH 7.4). A total of $0.5 \mathrm{~mL}$ of HBSS with glucose ( $25 \mathrm{mM}$, simulated fed state) in the presence or absence of either polyphenols (FP-95) $\left(0.26 \mathrm{mg} . \mathrm{mL}^{-1}\right)$ or polysaccharide-polyphenol conjugates $95{ }^{\circ} \mathrm{C}$ (PHWE-95) (10 mg.mL ${ }^{-1}$ ) were added to the apical side of the wells and $1.5 \mathrm{~mL}$ of HBSS without glucose was added to the basolateral side. After $2 \mathrm{~h}$ of incubation, samples were collected from the basolateral and apical side and then frozen $\left(-18^{\circ} \mathrm{C}\right)$ until GC-MS analysis of glucose content in them, following the method described in Section 2.3.1. Transport efficiency percentages were calculated according to the following formula: ((compound concentrations at the basolateral side overtime)/(compound concentrations at the apical side at the zero h) $) \times 100$.

Following permeability experiments, the cells were incubated with Lucifer yellow at a concentration of $100 \mu \mathrm{M}$ for $30 \mathrm{~min}$ on the apical side of the Transwell insert. HBSS was collected from the apical and basolateral sides at $t=0$ and $t=30 \mathrm{~min}$ and analysed by fluorescence at $458 \mathrm{~nm} / 530 \mathrm{~nm}$ using a FlexStation 3 Multi-Mode Microplate Reader (Molecular Devices, CA, USA). Lucifer yellow flux range for intact cell monolayers is typically $0.3 \%$ to $2 \%$ [46]. Thus, cell layers that transported more than $2 \%$ of Lucifer yellow to the basolateral compartment were judged as leaking and were discarded.

\subsection{Statistical Analysis}

Experiments were performed in triplicate ( 3 replicates for each triplicate, $n=9$, unless otherwise stated) to ensure the reproducibility of the results. Data are expressed as the mean \pm standard error of the mean (SEM) or mean \pm standard deviation (SD). One-way analysis of variance (one-way ANOVA) was used to determine statistically significant differences between the means of different experimental groups using the Tukey's multiple comparisons test. Differences were statistically significant at $p<0.05$. All statistical data were processed using GraphPad Prism version 8.0 for Windows.

\section{Results and Discussion}

\subsection{Characterization of Grape Pomace Free Polyphenols}

Free polyphenols were obtained from grape pomace through a hydroalcoholic solidliquid extraction (FP) and by pressurized hot water extraction at $95^{\circ} \mathrm{C}$ (FP-95). Although these fractions were recovered at comparable yields $(1.5 \%$ and $1.3 \%$ for FP and FP-95,

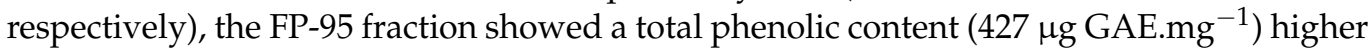
than the FP fraction $\left(254 \mu \mathrm{g}\right.$ GAE.mg $\left.{ }^{-1}\right)$. PHWE allows the physicochemical changes of water, decreasing the dielectric constant. The higher temperatures also favour water to wet and penetrate the cell-wall matrix and causes a decrease of the surface tension and viscosity, improving analyte diffusion rate and mass-transfer kinetics. Considering the moderate experimental conditions applied and the use of water, this may be considered a low energy consumption process with no toxicity associated.

The FP-95 fraction also presented the highest antioxidant activity, almost two-fold than the observed for FP, being in line with the highest value of total polyphenols determined in this extract.

UPLC-DAD analysis showed that FP and FP-95 fractions presented similar amounts of anthocyanins $(p>0.05)$, with the dominant anthocyanin being malvidin-3-O-glucoside 
(major red grape anthocyanin) and its acylated derivatives such as malvidin-3-O-6"-pcoumaroyl-glucoside and malvidin-3-O-6"-acetyl-glucoside (Supplementary Materials, Table S1 and Figure S1). Delphinidin-3-O-glucoside, peonidin-3-O-glucoside and petunidin3-O-glucoside, as well as acylated derivatives (petunidin-3-O-6"-acetyl-glucoside, delphinidin$3-O-6^{\prime \prime}-p$-coumaroyl-glucoside, petunidin-3-O-6"-p-coumaroyl-glucoside and malvidin-3$O-6 "$-caffeoyl-glucoside), were also detected, but in minor amounts. Anthocyanin-derived pigments such as carboxypyranomalvidin-3-O-glucoside, carboxypyranomalvidin-3-Oacetyl-glucoside and carboxypyranopetunidin-3-O-acetyl-glucoside were also detected. These pigments result from the reaction of anthocyanins with yeast metabolites during the fermentation process [47].

Polymeric anthocyanins can also be formed during grape fermentation from the reaction between monomeric anthocyanins and other phenolic compounds. Acetaldehydemediated condensation, copigmentation and self-association [48] are the major reactions considered to be responsible for the formation of polymeric pigments. Thus, the percentage of polymeric colour was determined considering the ratio between polymerized coloured anthocyanins and colour density. This value was much higher for FP extract (about 80\%), an indication of a higher proportion of polymeric anthocyanins than for FP-95. Polymeric anthocyanins generally have higher hydrophobicity and larger molecular weight compared to monomeric anthocyanins, thus being preferably extracted by organic solvents. They also typically show poor solubility in acidic aqueous systems, maybe due to the other compounds bound to anthocyanins [49]. In fact, FP solutions presented visible suspensions, even at lower concentrations, suggesting lower solubility of the solutes. FP-95 extract showed a much lower percentage of polymeric colour (30\%), indicating the preferential recovery of monomeric anthocyanins.

Besides anthocyanins, free polyphenolic fractions also presented monomeric and oligomeric flavan-3-ols and conjugated phenolic compounds with sugar moieties (Supplementary Materials, Table S2 and Figure S2). Low molecular weight polyphenols, such as gallic acid $(\mathrm{m} / \mathrm{z} 169)$ and coumaric acid-3-O-glucoside $(\mathrm{m} / \mathrm{z} 325)$, could be detected in both fraction with these compounds corresponding to minor components (approximately 4 and $5 \%$ of the total amount of detected phenolic compounds for FP and FP-95, respectively).

Regarding proanthocyanidins, they were detected in a much higher proportion. The LC-DAD/ESI-MS analysis allowed to identify monomers (catechin and epicatechin, pseudo-molecular ion $\mathrm{m} / \mathrm{z} 289$ ), oligomeric proanthocyanidins (dimers and trimers, pseudomolecular ion $m / z 577$ and 865, respectively) and gallate derivatives in both fractions (pseudo-molecular ion $m / z 729$ and 881, mono and digallate derivative, respectively). Gallate trimers and tetramers could also be detected in these fractions, but in smaller amounts (pseudo-molecular ion $m / z 1017$ and 1153, respectively). Additionally, the presence of the pseudo-molecular ions at $\mathrm{m} / \mathrm{z} 593$ and 897 indicates the presence of prodelphinidins in grape pomace. Compound 3, with the pseudo-molecular ion at $\mathrm{m} / \mathrm{z} 593$ and with characteristic fragments at $m / z 467,425$ and 407 , suggested the presence of a dimeric proanthocyanidin formed with one (epi)gallocatechin unit and one (epi)catechin unit. Compound 4, with the pseudo-molecular ion at $m / z$ 897, suggested the presence of a trimeric proanthocyanidin with two (epi)gallocatechin units and one (epi)catechin unit [50,51].

Four flavonols were detected in grape pomace free polyphenolic fractions $(8-9 \%$ of the total amount of detected phenolic compounds for FP and FP-95, respectively), with quercetin-3-O-glucuronide as the major one. Quercetin-3-O-hexoside, myricetin-3-Ohexoside and myricetin-3-O-arabinoside could also be detected, but in lower amounts.

In general, pressurized hot water extraction allowed us to obtain a fraction rich in proanthocyanidins, with minor amounts of low molecular weight phenolics and flavonols, which could be correlated with the highest antioxidant activity observed for this fraction. Besides polyphenols, both fractions were also shown to present similar amounts of proteins (approximately $10 \%$ ) and simple sugars $(<1 \%)$. 


\subsection{Characterization of Grape Pomace Polysaccharide-Polyphenol Conjugates}

As the physicochemical characteristics of the macromolecular fraction, such as molecular weight, chemical composition, and related bioactivities, have been shown to be affected by the extraction methodology $[21,52,53]$, alkaline and pressurized hot water extractions were tested to recover polysaccharide-polyphenol complexes. A preliminary evaluation of the extracts allowed to observe some physical differences. Although the three fractions presented a fiber structure, the fraction obtained by alkaline extraction (AE) resulted in a fiber structure with a beige colour. On the other hand, conjugates obtained from PHWE (PHWE-95 and PHWE-120) presented a reddish colour (more significant for the lowest temperature), a possible indication of the presence of anthocyanins co-extracted with the fiber matrix.

The high molecular weight material isolated by dialysis accounted for 1.3 to $3.4 \%$ (g fraction/g dried grape pomace), with the highest value corresponding to the PHWE-120. This was attributed to the higher temperatures used, which promoted a higher degradation of the cell wall structure, and thus, a higher solubilization of polymeric material than when performing the extraction at $95^{\circ} \mathrm{C}$ or alkaline extractions at room temperature (Table 1).

Table 1. Chemical composition and antioxidant activity of free polyphenols and polysaccharide-polyphenol conjugates recovered from red grape pomace by solid-liquid extraction and pressurized hot water extraction. Results are presented as mean value \pm standard deviation. For free polyphenols fractions or polysaccharide-polyphenol conjugates fractions, columns with the same symbol do not present statistical differences $(p>0.05)$.

\begin{tabular}{|c|c|c|c|c|c|}
\hline Identification & FP & FP-95 & $\mathrm{AE}$ & PHWE-95 & PHWE-120 \\
\hline Yield (\%) & 1.5 & 1.3 & 2.6 & 1.3 & 3.4 \\
\hline $\begin{array}{c}\text { Anthocyanins } \\
\left(\mu \mathrm{g} \mathrm{Mv3Glc} \mathrm{equi.mg}{ }^{-1}\right)\end{array}$ & $121 \pm 14^{*}$ & $100 \pm 13 *$ & - & - & - \\
\hline Polymeric colour (\%) & $80.2 \pm 0.2 *$ & $30 \pm 1^{* *}$ & - & - & - \\
\hline $\begin{array}{l}\text { Non-anthocyanic compounds } \\
\quad\left(\mu \mathrm{g} \text { GAE.mg }{ }^{-1}\right)\end{array}$ & $30 \pm 10 *$ & $197 \pm 13^{* *}$ & - & - & - \\
\hline $\begin{array}{c}\text { Protein content } \\
\left(\mu \mathrm{g}^{\mathrm{BSA}} \text { equi.mg }{ }^{-1}\right)\end{array}$ & $93 \pm 3^{*}$ & $105 \pm 9 *$ & $9 \pm 2 *$ & $10.4 \pm 0.3^{*}$ & $14.2 \pm 0.5^{* *}$ \\
\hline $\begin{array}{c}\text { Sugar content } \\
\left(\mu \mathrm{g} \text { Glucose equi.mg }{ }^{-1}\right)\end{array}$ & $6.0 \pm 0.3 *$ & $6.7 \pm 2 *$ & - & - & - \\
\hline $\begin{array}{l}\text { Phenolic compounds } \\
\quad\left(\mu \mathrm{g} \text { GAE. } \mathrm{mg}^{-1}\right)\end{array}$ & $254 \pm 8 *$ & $427 \pm 24^{* *}$ & $106 \pm 2 *$ & $108 \pm 5 *$ *\# & $111 \pm 2^{\#}$ \\
\hline $\begin{array}{l}\text { Antioxidant activity } \\
\text { ( } \mu \mathrm{M} \text { Trolox equi.) }\end{array}$ & $2.6 \pm 0.7^{*}$ & $6.2 \pm 0.3^{* *}$ & $15 \pm 2$ * & $12 \pm 2 *$ & $16 \pm 2 *$ \\
\hline $\begin{array}{l}\text { Antiradicalar activity } \\
(\mu \mathrm{M} \text { Trolox equi.) }\end{array}$ & $13.7 \pm 0.7^{*}$ & $25 \pm 2^{* *}$ & $16 \pm 3^{*}$ & $27 \pm 1^{* *}$ & $25 \pm 2 * *$ \\
\hline
\end{tabular}

Sugar analysis revealed that the polymeric material of AE, PHWE-95 and PHWE120 was mostly represented by polysaccharides (61\% to $69 \%$ ), differing on their sugar composition (Table 2). The AE polysaccharides were richer in GalA (79 $\mathrm{mol} \%)$, a sugar typical of galacturonan chains of pectic polysaccharides found in grape pomace [24]. The polysaccharides of PHWE-95 were also rich in GalA (59 mol\%) but presented a higher proportion of neutral sugars such as Ara $(20 \mathrm{~mol} \%)$ and Gal $(8 \mathrm{~mol} \%)$ characteristic of arabinans and galactan side chains of pectic polysaccharides of grape skin cell walls [54,55]. These sugars were also found in the PHWE-120 extract, alongside with Glc (27 mol\%), which has been also reported for skin HEPES-soluble polysaccharides [55]. This is the same outcome from the solubilization of xyloglucan degraded material under high temperatures as reported for apple pomace [56]. 
Table 2. Yield, total carbohydrates, and monosaccharide composition (molar \%) of polysaccharide-polyphenol conjugates (AE, PHWE-95, PWWE-120). Results are expressed as mean values \pm standard deviation.

\begin{tabular}{|c|c|c|c|c|c|c|c|c|c|}
\hline \multirow{2}{*}{ Sample } & \multicolumn{8}{|c|}{ Carbohydrate Composition (Molar \%) } & \multirow{2}{*}{$\begin{array}{c}\text { Total Carbohydrates } \\
\left(\mathrm{mg} \cdot \mathrm{g}^{-1}\right)\end{array}$} \\
\hline & Rha & Fuc & Ara & Xyl & Man & Gal & Glc & GalA & \\
\hline $\mathrm{AE}$ & $1 \pm 0$ & $1 \pm 0$ & $9 \pm 0$ & $1 \pm 0$ & $1 \pm 1$ & $4 \pm 1$ & $4 \pm 1$ & $79 \pm 3$ & $687 \pm 4$ \\
\hline PHWE-95 & $1 \pm 0$ & - & $20 \pm 2$ & $2 \pm 0$ & $5 \pm 0$ & $8 \pm 0$ & $7 \pm 1$ & $59 \pm 1$ & $668 \pm 43$ \\
\hline PHWE-120 & $1 \pm 0$ & - & $2 \pm 0$ & - & $9 \pm 0$ & $4 \pm 0$ & $27 \pm 1$ & $58 \pm 1$ & $608 \pm 4$ \\
\hline
\end{tabular}

Alongside with polysaccharides, polyphenols were found to be present in all extracts at a proportion of 106 to 108 and $111 \mu \mathrm{g}$ GAE equivalents per mg of extract for AE, PHWE95 and PHWE-120, respectively. These compounds were not removed during the washing step with methanol and after the extensive dialysis, thus suggesting that they are part of a macromolecular structure composed by polysaccharides. In fact, the chaotropic nature of methanol, which causes the cleavage of hydrogen bounds and hydrophobic interactions between polyphenols and polysaccharides [57], might be an indication of the existence of covalently linked polysaccharide-polyphenols complexes, instead of non-covalent complexes resulting from biosynthetic pathways or due to grape pomace processing, as previously observed for apple pomace [39]. Proteins were also found to be present at a proportion of $1 \%$ (Table 1 ).

To understand the nature of the polysaccharide-polyphenol conjugates, the UV-Vis spectra of the samples were obtained. Conjugate fractions showed a band around $280 \mathrm{~nm}$ which is likely to arise, besides proteins, from the presence of aromatic structures of phenolic compounds ( $\mathrm{C}=\mathrm{C}$ bonds of aromatic rings). Another band with lower intensity at approximately $330 \mathrm{~nm}$ was also present in the spectra, typically related with the presence of subunits of phenolic conjugated to each other ( $\mathrm{C}=\mathrm{C}$ bonds of the aromatic structure) [58]. The PHWE extracts also showed a band around $520-530 \mathrm{~nm}$, characteristic of the presence of anthocyanins (Figure 1A). For AE extract, the alkaline extraction performed without $\mathrm{NaBH}_{4}$ may have induced polyphenols oxidation and degradation, explaining the lack of this band. However, despite the band around $520-530 \mathrm{~nm}$, no chromatographic peaks could be detected by HPLC-DAD, suggesting, as reported for melanoidins, the covalent linkage of polyphenols to the polymeric material [40], instead of an association mediated by non-covalent interactions. Acid hydrolysis of the polymeric material resulted in an increase in the band around $520 \mathrm{~nm}$ (Figure 1B). Additionally, chromatographic peaks could be detected. The MS spectra showed characteristic signals at $\mathrm{m} / \mathrm{z} 287,303$ and 331, corresponding to cyanidin, delphinidin and malvidin aglycones, respectively. The presence of cyanidin and delphinidin aglycones could arise as an artefact from the hydrolysis procedure which may have converted proanthocyanidins in anthocyanidins due to acidic hydrolysis at higher temperatures. This agrees with previous results, where polymeric tannins are the most common phenolic compounds linked to fruits dietary fibers [59]. However, the detection of the pseudo-molecular ion $\mathrm{m} / \mathrm{z} 331$ corresponding to malvidin aglycone shows that besides proanthocyanidins, anthocyanic pigments might also be bound to the polymeric material, especially pectic polysaccharides. The occurrence of these phenolic structures was in accordance with the antioxidant activity observed for all fractions, as measured by the DPPH and FRAP assays.

Regarding the DPPH-radical assay, the PHWE polysaccharide-polyphenol complexes presented a similar scavenging capacity $(p>0.05)$, which was, however, higher than $\mathrm{AE}$ polysaccharide-polyphenol complexes $(16 \pm 3 ; 27 \pm 1$ and $25 \pm 2 \mathrm{mM}$ Trolox equivalents for AE, PHWE-95 and PHWE-120, respectively). However, no differences $(p>0.05)$ were observed for the FRAP assay (15 $\pm 2 ; 12 \pm 2$ and $16 \pm 2$, mM Trolox equivalents, for AE, PHWE-95 and PHWE-120, respectively). The differences in the antioxidant capacity of the three conjugates results from the type of polyphenols adsorbed and the extent of carbohydrates able to link or adsorb polyphenols. Globally, these values were noticeably 
higher than that of the free polyphenol's extracts (FP and FP-95), possibly due to the cumulative effect of polysaccharides to samples' weight.

$\mathbf{A}$
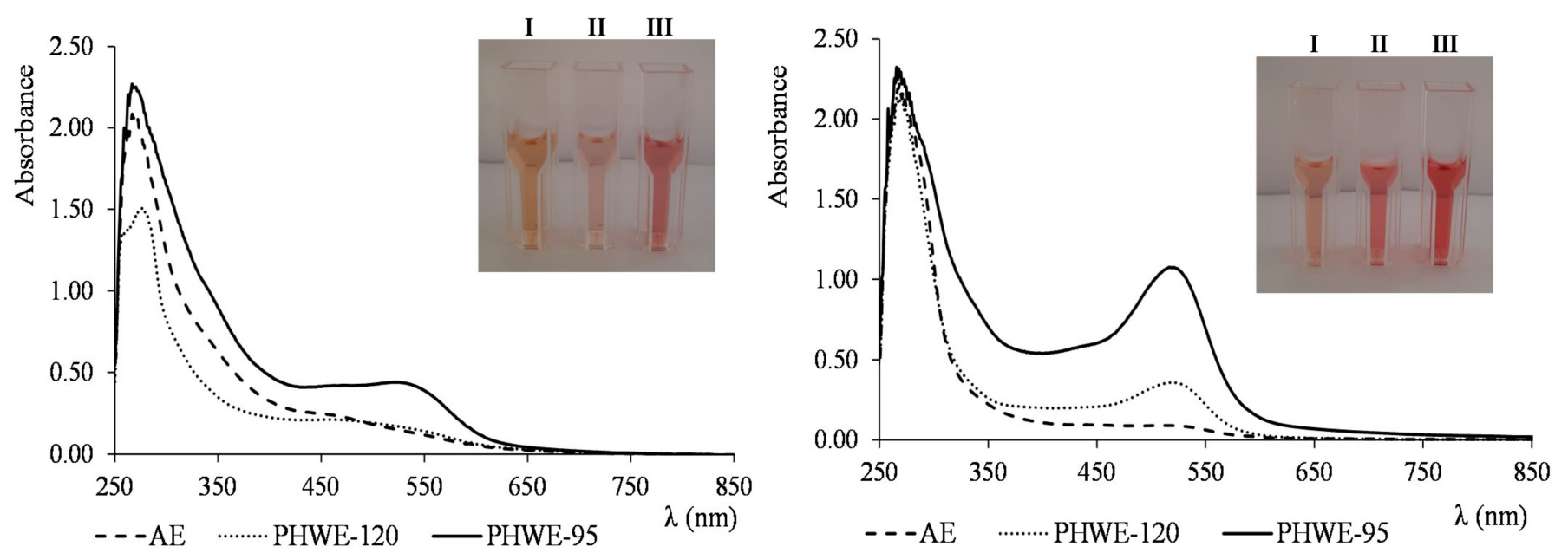

Figure 1. UV-Visible spectra of polysaccharide-polyphenol conjugates fractions (A) before acidic hydrolysis and (B) after acidic hydrolysis. I, II and III cells correspond to AE, PHWE-120 and PHWE-95 extracts, respectively.

\subsection{Evaluation of the Potential Antidibetic Effects}

\subsubsection{Inhibition of $\alpha$-Amylase and $\alpha$-Glucosidase Activity}

Polyphenols and plant polysaccharides may affect starch polysaccharides digestibility by inhibiting $\alpha$-amylase and $\alpha$-glucosidase [60], and consequently, the rate of glucose release in the bloodstream, a feature imbalanced in metabolic disorders and associated diseases. For that reason, the inhibitory activity of grape pomace polyphenols and polysaccharide-polyphenol conjugates on these enzymes was studied and compared to the effect of acarbose (positive control). The inhibition of $\alpha$-amylase and a-glucosidase was dose-dependent and considerably different among free and polysaccharide bondpolyphenolic fractions (Table 3). Despite the lower amount of polyphenols observed in the extract obtained by $50 \%$ ethanol extraction (FP), it presented a similar inhibitory activity as the polyphenolic fraction obtained by pressurized hot water extraction at $95{ }^{\circ} \mathrm{C}$ (FP-95). This can be attributed to the presence of polymerized pigments that, as reported for grape seed procyanidins [61], present a higher inhibitory activity when compared to the lower molecular weight counterparts. Also, the presence of larger molecules may confer to these pigments a greater chemical stability in mildly to neutrally aqueous environments, which may induce similar inhibitory activity, despite the lower amount. Free polyphenol inhibition may possibly be due to the capability of free polyphenols, rich in hydroxyl groups, to interfere with substrate-enzyme binding, by blocking the active sites of the enzymes or through the non-specific interactions at different enzymes domains, via hydrogen, hydrophobic or electrostatic interactions. These extracts provided a more pronounced inhibitory effect on $\alpha$-glucosidase, compared with $\alpha$-amylase, similarly to the results previously reported. According to the Rasouli et al. (2017) work [62], several polyphenols have shown a high affinity towards $\alpha$-glucosidase active sites, such as epicatechin, cyanidin, ferulic and caffeic acid, quercetin or syringic acid. Conversely, inhibition of $\alpha$-amylase activity was achieved by fewer classes of polyphenols. FP and FP-95 extracts were composed mainly of proanthocyanidins, anthocyanins and low molecular weight polyphenols and some flavonols which may explain the higher affinity to $\alpha$-glucosidase active sites and increased inhibition activity. Additionally, the $\mathrm{IC}_{50}$ values observed for a-glucosidase activity, were significantly lower than acarbose (current available drug), a very remarkable aspect related to the potential application of these extracts in the development of functional foods for the management of T2DM. 
Table 3. $\mathrm{IC}_{50}$ of $\alpha$-Amylase and $\alpha$-glucosidase inhibition by free polyphenols extracts (FP, FP-95) and polysaccharidepolyphenol extracts (AE, PHWE-95, PHWE-120). Results are presented as the mean \pm standard error of the mean (SEM) $(n=9)$. Values with the symbol $\left(^{*}\right)$ are different from the positive control $(p<0.05)$. For the same enzyme, columns with different letter are significantly different $(p<0.05)$.

\begin{tabular}{ccccccc}
\hline & & \multicolumn{4}{c}{ IC $_{50} \pm$ SEM $\left(\mu \mathrm{g} . \mathrm{mL}^{-1}\right)$} \\
\hline & Positive Control & \multicolumn{2}{c}{ Free Polyphenols Extracts } & \multicolumn{3}{c}{ Polysaccharide-Polyphenol Extracts } \\
\hline & Acarbose & FP & FP-95 & AE & PHWE-95 & PHWE-120 \\
\hline$\alpha$-amylase & $2.5 \pm 0.1$ & $25 \pm 1^{*, \mathrm{a}}$ & $27.5 \pm 0.9^{*, \mathrm{a}}$ & $2139 \pm 13^{*, \mathrm{~b}}$ & $572 \pm 22^{*, \mathrm{c}}$ & $939 \pm 37^{*, \mathrm{~d}}$ \\
$\alpha$-glucosidase & $123 \pm 67$ & $0.48 \pm 0.02^{*, \mathrm{a}}$ & $0.45 \pm 0.02^{*, \mathrm{a}}$ & $2.7 \pm 0.1^{*, \mathrm{~b}}$ & $4.0 \pm 0.2^{*, \mathrm{c}}$ & $5.2 \pm 0.1^{*, \mathrm{~d}}$ \\
\hline
\end{tabular}

Polyphenol-polysaccharide conjugates showed an inhibitory effect on $\alpha$-amylase 20to 80 -fold lower than the free polyphenolic fractions and 10-fold lower for a-glucosidase. The macromolecular nature of polysaccharide-polyphenol conjugates clearly affected polyphenols' capability to modulate enzyme activity, possibly due to steric hindrance caused by the linkage to polysaccharides, thus resulting in a lower inhibition activity. In fact, if the $\mathrm{IC}_{50}$ values for a-amylase inhibition, were expressed in polyphenol concentration (GAE) instead of extract concentration, a higher $\mathrm{IC}_{50}$ value could still be observed for the conjugates, suggesting the unfavorable role of the polysaccharide part of the conjugate for the binding (estimated $\mathrm{IC}_{50}$ values of $6.25 ; 11.8 ; 227 ; 62$; and $103 \mu \mathrm{g} . \mathrm{mL}^{-1}$ for FP, FP-95, AE, PHWE-95 and PHWE-120, respectively).

Additionally, the methodology applied for polysaccharide-polyphenol conjugates extraction, allowed us to obtain fractions with different inhibitory activity towards $\alpha$ amylase. Oxidized polyphenolic-polysaccharide structures obtained by alkaline extraction resulted in significantly lower inhibition activity. Conversely, non-oxidized polyphenolic structures, obtained by PHWE, showed a significantly higher inhibition activity (lower $\left.\mathrm{IC}_{50}\right)$. PHWE-120 extract, with xyloglucan domains and lower amounts of neutral sugars, showed lower inhibition activity compared to PHWE-95 extract, despite similar polyphenolic content. This suggests that branched domains richer in neutral sugars recovered at lower temperatures, promote a higher ability of polyphenols bound to polysaccharides to inhibit a-amylase activity. Regarding a-glucosidase inhibitory activity, an opposite trend could be observed with oxidized polysaccharide-polyphenol structures richer in homogalacturonan domains showing a higher inhibition activity.

\subsubsection{Advanced Glycation End Products (AGEs)}

The antiglycation activities of free polyphenols and polysaccharide-polyphenol conjugates were investigated and compared to the activity of aminoguanidine (positive control), a common therapeutic drug used to prevent the formation of AGE.

Polyphenol extract obtained by pressurized hot water extraction (FP-95) presented antiglycation activity similar $(p>0.05)$ to aminoguanidine $(\mathrm{AG})$, with an $\mathrm{IC}_{50}$ value of $209 \mu . \mathrm{mL}^{-1}$ (Table 4). This comparable activity enhances the importance of the inclusion of grape pomace polyphenolic extract in our daily diet. Free polyphenol extract obtained by solid-liquid extraction (FP) presented a lower inhibition activity as shown by the higher $\mathrm{IC}_{50}$ value $\left(571 \mu \mathrm{g} . \mathrm{mL}^{-1}\right)$. This could be related to the lower antioxidant activity of this fraction when compared to the FP-95 fraction (Table 1). 
Table 4. $\mathrm{IC}_{50}$ of AGE inhibition by polyphenols extracts (FP and FP-95) and polysaccharide-polyphenols conjugates (AE, PHWE-95, PHWE-120). Results are presented as the mean \pm standard error of the mean (SEM) $(n=9)$. Values with the symbol $(*)$ are different from the positive control $(p<0.05)$. Columns with different letter are significantly different $(p<0.05)$.

\begin{tabular}{cccccc}
\hline \multicolumn{7}{c}{ IC $_{50} \pm$ SEM $\left(\mu \mathrm{g} . \mathrm{mL}^{-1}\right)$} \\
\hline Aminoguanidine & FP & FP-95 & AE & PHWE-95 & PHWE-120 \\
\hline $230 \pm 12$ & $571 \pm 32^{*, \mathrm{a}}$ & $209 \pm 21^{\mathrm{b}}$ & $1036 \pm 79^{*, \mathrm{c}}$ & $1270 \pm 65^{*, \mathrm{~d}}$ & $5129 \pm 594^{*, \mathrm{e}}$ \\
\hline
\end{tabular}

For polysaccharide-polyphenol conjugates, the $\mathrm{IC}_{50}$ values obtained was 2- to 10 fold higher when compared to polyphenolic fractions, in agreement with the data for the enzymatic inhibition essays. The complexes obtained by alkaline extraction (AE) and PHWE obtained at $95{ }^{\circ} \mathrm{C}$ presented a comparable antiglycation activity but lower than that of the complexes obtained by PHWE at $120^{\circ} \mathrm{C}$ (PHWE-120). Although polysaccharidepolyphenol fractions generally presented higher antioxidant activity (particularly free radical scavenging activity), the lower antiglycation activity compared to free polyphenols may be due to the prevalence of other mechanisms of action to inhibit glycation and formation of AGE in the polyphenolic extracts. In fact, anthocyanin-3-glucosides or phenolic acids may bind competitively to proteins by non-covalent interactions (hydrogen bonds or van der Waals forces), thus protecting their structural integrity and inhibiting nonenzymatic glycation. Additionally, some phenolic compounds attenuate the expression of AGE receptor-associated signaling, while others may trap active dicarbonyl compounds or chelate metal ions $[63,64]$. Expressing the antiglycation activity as GAE instead of extract concentration resulted in a similar $\mathrm{IC}_{50}$ between free polyphenols and polysaccharidepolyphenols conjugate (estimated $\mathrm{IC}_{50}$ values of $145 ; 89 ; 110 ; 137$; and $569 \mu \mathrm{g} . \mathrm{mL}^{-1}$ for $\mathrm{FP}$, FP-95, AE, PHWE-95 and PHWE-120, respectively), thus suggesting the reduced impact of polysaccharides for the global antiglycation effect of the conjugates. However, despite the lower impact of polysaccharide moieties, polyphenols associated with macromolecular structures are poorly bioavailable in the upper gut and reach the colon, thus contributing to the target delivery and bioactivity of polyphenols.

\subsubsection{Glucose Uptake}

To measure glucose uptake, an intestinal epithelial layer of Caco-2 cells was cultured on a Transwell system and glucose transport was measured after 120 min by GC-MS. To validate these experiments, a transport assay with Lucifer yellow was performed. The observed medium $\%$ flux $(0.55 \pm 0.04 \%)$, less than $2 \%$, allowed the validation of the experiments [46].

With Hanks buffer containing $25 \mathrm{mM}$ glucose and no polyphenols or polysaccharidepolyphenol conjugates, it was possible to quantify $0.6 \mathrm{mM}$ of glucose in the basolateral side (approximately $8 \%$ transported glucose) after $120 \mathrm{~min}$, corresponding to an apparent permeability of $1.50 \times 10^{-5} \pm 1.55 \times 10^{-6} \mathrm{~cm} \cdot \mathrm{s}^{-1}$ (Figure 2). A similar glucose transport percentage has been previously reported [65]. Glucose transport was found to be impacted by the presence of free polyphenolic fraction (FP-95), with a significative reduction being observed in the uptake of glucose for $4.77 \times 10^{-6} \pm 2.26 \times 10^{-7} \mathrm{~cm} \cdot \mathrm{s}^{-1}$ (approximately $2.6 \%$ transported glucose) after $120 \mathrm{~min}$ of incubation $(p<0.001)$. This reduction may be attributed to the presence of glycosylated anthocyanins or flavonols, that inhibit the active glucose transport by sodium-dependent glucose co-transporters 1 (SGLT1) and glucose transporter 2 (GLUT2) by direct competition and also at a gene level [66]. Other polyphenols like proanthocyanidins are also able to inhibit facilitated glucose uptake via steric hindrance [67]. 


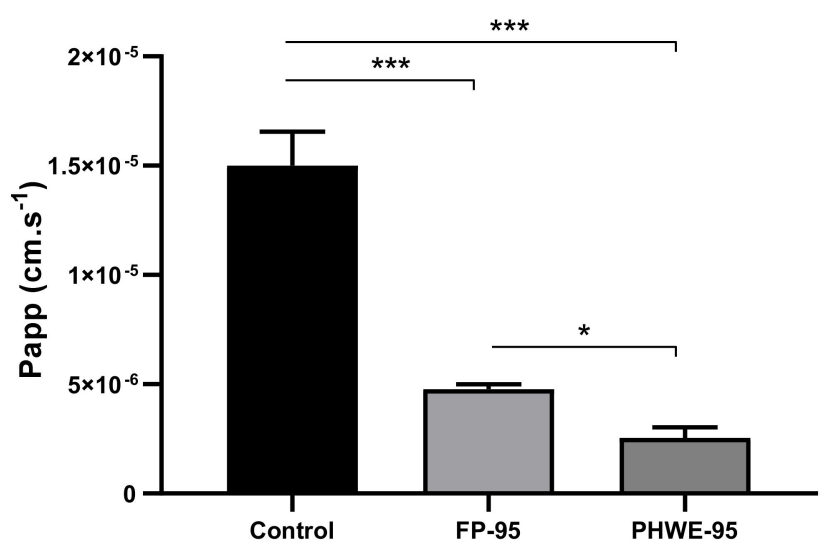

Figure 2. Glucose permeability coefficient $\left(\mathrm{cm} . \mathrm{s}^{-1}\right)$ in the presence of a FP-95 $\left(0.26 \mathrm{mg} . \mathrm{mL}^{-1}\right)$ or PHWE-95 (10 mg.mL $\left.{ }^{-1}\right)$. In all samples glucose was added to the apical side at $25 \mathrm{mM}$ glucose in order to simulate fed state and basolateral side was filled with Hanks glucose-free buffer. Results are presented as the mean \pm standard error of the mean (SEM) $(n=8)$. Significative differences versus control samples *** $p<0.001$; significative difference between FP-95 and PHWE-95* $p<0.05$.

Considering the polysaccharide-polyphenol conjugates, a higher concentration was tested since only $10 \%$ of the total amount corresponded to polyphenolic content. In this case, an even lower glucose uptake was observed, suggesting that besides the contribution of polyphenols, other factors were affecting glucose uptake. Also, a significative difference in the apparent coefficient was determined between the two extracts, highlighting for the dual effect of the conjugates $(p<0.05)$ due to their polyphenolic and polysaccharide nature. Some reports have already shown the intestinal uptake of certain types of polysaccharides against Caco-2 monolayer cells [65,68], with this transport being time-dependent and occurring in the form of macromolecules. Additionally, the results presented by Cai et al. (2017) [65] clearly showed that polysaccharides from Lycium barbarum L. inhibit glucose transport across the Caco-2 monolayer cells mainly by competing for SGLT1 transporters (to a less extension, by GLUT2 competition) and also by down regulating the expression of SGLT-1. The increased viscosity at high polysaccharide concentration, may also impair glucose diffusion and transport.

\section{Conclusions}

Polyphenols, either as free or conjugated with polysaccharides, were isolated from grape pomace. PHWE was shown to be a suitable methodology, allowing us to obtain both bioactives in good yields without the use of organic solvents. Polyphenols conjugated with branched polysaccharides rich in neutral sugars were obtained by PHWE. Meanwhile, oxidized polyphenol-polysaccharide structures were obtained by alkaline extraction. Polysaccharides-polyphenols conjugates showed an antidiabetic potential, although lower than free polyphenols. While polyphenols bound to polysaccharides with branched sidechains were able to attenuate glucose transport through Caco-2 human cell monolayers and showed a higher ability to reduce a-amylase activity, oxidized polyphenolic structures had a higher impact on a-glucosidase activity and on the antiglycation effect of the polysaccharide-polyphenol conjugates. Bearing this in mind, grape pomace polysaccharide-polyphenol conjugates may present a valid option in controlling blood glucose levels.

This work will contribute to the knowledge related to glucose transepithelial transport, enzyme and AGEs inhibition by polysaccharide-polyphenol conjugates. The understanding of the nutritional consequences of polysaccharide-polyphenol complexes in the colon and the convincing demonstration of the existence of covalent bonds between flavonoids and cell wall polysaccharides by structural elucidation of molecules are also fundamental aspects that should be addressed in the near future. 
Supplementary Materials: The following are available online at https:/ / www.mdpi.com/article/10 $.3390 /$ nu13124495/s1, Table S1. HPLC-DAD /ESI-MS profile of anthocyanic compounds detected in free polyphenol fractions obtained from grape pomace (CFP and FP-95); Figure S1. HPLC-DAD /ESI-MS chromatogram of free polyphenols fractions (anthocyanic compounds) obtained from grape pomace; Table S2. HPLC-DAD /ESI-MS profile of nonanthocyanic compounds (low molecular weight phenolic compounds, flavan-3-ols and flavonols) detected in free polyphenol fractions obtained from grape pomace (CFP and FP-95); Figure S2. HPLC-DAD /ESI-MS chromatogram of free polyphenols fractions (non-anthocyanic compounds) obtained from grape pomace.

Author Contributions: Conceptualization, A.F. and I.F.; methodology, F.C., A.F.P., P.A.R.F., A.F. and I.F.; validation, A.F.P., P.A.R.F., A.F. and I.F.; formal analysis, F.C., A.F.P., P.A.R.F., A.F. and I.F.; investigation, F.C., A.F.P., P.A.R.F., A.F. and I.F.; data curation, A.F. and I.F.; writing-original draft preparation, A.F., I.F., A.F.P. and P.A.R.F.; writing-review and editing, M.A.C., N.M. and V.d.F.; visualization, F.C., A.F.P., P.A.R.F., A.F. and I.F.; supervision, A.F. and I.F.; project administration, V.d.F.; funding acquisition, V.d.F. All authors have read and agreed to the published version of the manuscript

Funding: This research was funded by AgriFood XXI I\&DT project (NORTE-01-0145-FEDER-000041) cofinanced by the European Regional Development Fund (ERDF) through the NORTE2020 (Programa Operacional Regional do Norte 2014/2020).
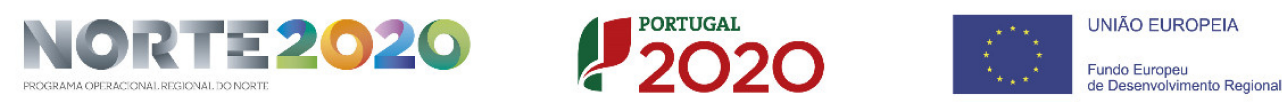

Informed Consent Statement: Not applicable.

Data Availability Statement: Not applicable.

Acknowledgments: The authors acknowledges the FCT foundation for the financial support of the research contracts (CEECIND/00029/2018/CP1545/CT0010, 2020.01614.CEECIND/CP1596/CT0007 and SFRH/BPD/86173/2012) and UIDB/50006/2020, through national funds and cofinanced by FEDER, under the Partnership Agreement PT2020.This research was supported by cLabel + Project (POCI-01-0247-FEDER-046080) cofinanced by the European Regional Development Fund (ERDF), through the COMPETE 2020-Incentive System to Research and Technological Development, within the Portugal 2020 Competitiveness and Internationalization Operational Program.
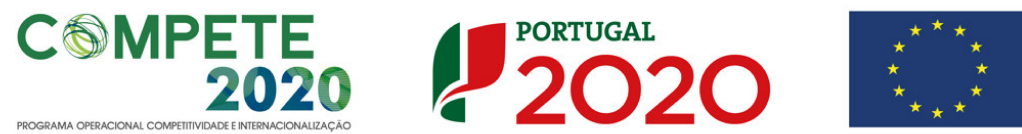

UNIÃO EUROPEIA

Fundos Europeus Estruturais e de Investimento

Conflicts of Interest: The authors declare no conflict of interest.

\section{References}

1. Les, F.; Cásedas, G.; Gómez, C.; Moliner, C.; Valero, M.S.; López, V. The role of anthocyanins as antidiabetic agents: From molecular mechanisms to in vivo and human studies. J. Physiol. Biochem. 2021, 77, 109-131. [CrossRef] [PubMed]

2. Wu, J.; Shi, S.; Wang, H.; Wang, S. Mechanisms underlying the effect of polysaccharides in the treatment of type 2 diabetes: A review. Carbohydr. Polym. 2016, 144, 474-494. [CrossRef] [PubMed]

3. Anhê, F.F.; Desjardins, Y.; Pilon, G.; Dudonné, S.; Genovese, M.I.; Lajolo, F.M.; Marette, A. Polyphenols and type 2 diabetes: A prospective review. PharmaNutrition 2013, 1, 105-114. [CrossRef]

4. Bessa-Pereira, C.; Dias, R.; Brandão, E.; Mateus, N.; de Freitas, V.; Soares, S.; Pérez-Gregorio, R. Eat Tasty and Healthy: Role of Polyphenol in Functional Foods. In Functional Foods; IntechOpen: London, UK, 2021.

5. Ding, Y.; Morozova, K.; Scampicchio, M.; Ferrentino, G. Non-Extractable Polyphenols from Food By-Products: Current Knowledge on Recovery, Characterisation, and Potential Applications. Processes 2020, 8, 925. [CrossRef]

6. Pinelo, M.; Arnous, A.; Meyer, A.S. Upgrading of grape skins: Significance of plant cell-wall structural components and extraction techniques for phenol release. Trends Food Sci. Technol. 2006, 17, 579-590. [CrossRef]

7. Pérez-Jiménez, J.; Díaz-Rubio, M.E.; Saura-Calixto, F. Chapter 10—Non-Extractable Polyphenols in Plant Foods: Nature, Isolation, and Analysis. In Polyphenols in Plants; Watson, R.R., Ed.; Academic Press: San Diego, CA, USA, 2014; pp. $203-218$. 
8. Wang, Z.; Li, S.; Ge, S.; Lin, S. Review of Distribution, Extraction Methods, and Health Benefits of Bound Phenolics in Food Plants. J. Agric. Food Chem. 2020, 68, 3330-3343. [CrossRef]

9. Renard, C.M.G.C.; Baron, A.; Guyot, S.; Drilleau, J.F. Interactions between apple cell walls and native apple polyphenols: Quantification and some consequences. Int. J. Biol. Macromol. 2001, 29, 115-125. [CrossRef]

10. Fry, S.C. Feruloylated pectins from the primary cell wall: Their structure and possible functions. Planta 1983, 157, 111-123. [CrossRef]

11. Ishii, T.; Hiroi, T. Isolation and characterization of feruloylated arabinoxylan oligosaccharides from bamboo shoot cell-walls. Carbohydr. Res. 1990, 196, 175-183. [CrossRef]

12. Le Bourvellec, C.; Guyot, S.; Renard, C.M.G.C. Interactions between apple (Malus $x$ domestica Borkh.) polyphenols and cell walls modulate the extractability of polysaccharides. Carbohydr. Polym. 2009, 75, 251-261. [CrossRef]

13. Cirillo, G.; Curcio, M.; Vittorio, O.; Iemma, F.; Restuccia, D.; Spizzirri, U.G.; Puoci, F.; Picci, N. Polyphenol Conjugates and Human Health: A Perspective Review. Crit. Rev. Food Sci. Nutr. 2016, 56, 326-337. [CrossRef]

14. Terry, P.; Giovannucci, E.; Michels, K.B.; Bergkvist, L.; Hansen, H.; Holmberg, L.; Wolk, A. Fruit, Vegetables, Dietary Fiber, and Risk of Colorectal Cancer. JNCI J. Natl. Cancer Inst. 2001, 93, 525-533. [CrossRef] [PubMed]

15. Anderson, J.W.; Baird, P.; Davis, R.H., Jr.; Ferreri, S.; Knudtson, M.; Koraym, A.; Waters, V.; Williams, C.L. Health benefits of dietary fiber. Nutr. Rev. 2009, 67, 188-205. [CrossRef] [PubMed]

16. Fermoso, F.G.; Serrano, A.; Alonso-Fariñas, B.; Fernández-Bolaños, J.; Borja, R.; Rodríguez-Gutiérrez, G. Valuable Compound Extraction, Anaerobic Digestion, and Composting: A Leading Biorefinery Approach for Agricultural Wastes. J. Agric. Food Chem. 2018, 66, 8451-8468. [CrossRef] [PubMed]

17. Gonçalves, F.J.; Fernandes, P.A.R.; Wessel, D.F.; Cardoso, S.M.; Rocha, S.M.; Coimbra, M.A. Interaction of wine mannoproteins and arabinogalactans with anthocyanins. Food Chem. 2018, 243, 1-10. [CrossRef] [PubMed]

18. Castro-Puyana, M.; Marina, M.L.; Plaza, M. Water as green extraction solvent: Principles and reasons for its use. Curr. Opin. Green Sustain. Chem. 2017, 5, 31-36. [CrossRef]

19. Ekman, A.; Campos, M.; Lindahl, S.; Co, M.; Börjesson, P.; Karlsson, E.N.; Turner, C. Bioresource utilisation by sustainable technologies in new value-added biorefinery concepts-Two case studies from food and forest industry. J. Clean. Prod. 2013, 57, 46-58. [CrossRef]

20. Rodríguez-Meizoso, I.; Castro-Puyana, M.; Börjesson, P.; Mendiola, J.A.; Turner, C.; Ibáñez, E. Life cycle assessment of green pilot-scale extraction processes to obtain potent antioxidants from rosemary leaves. J. Supercrit. Fluids 2012, 72, 205-212. [CrossRef]

21. Liu, J.; Bai, R.; Liu, Y.; Zhang, X.; Kan, J.; Jin, C. Isolation, structural characterization and bioactivities of naturally occurring polysaccharide-polyphenolic conjugates from medicinal plants-A review. Int. J. Biol. Macromol. 2018, 107, 2242-2250. [CrossRef] [PubMed]

22. Plaza, M.; Turner, C. Pressurized hot water extraction of bioactives. TrAC Trends Anal. Chem. 2015, 71, 39-54. [CrossRef]

23. Pawlaczyk-Graja, I.; Balicki, S.; Wilk, K.A. Effect of various extraction methods on the structure of polyphenolic-polysaccharide conjugates from Fragaria vesca L. leaf. Int. J. Biol. Macromol. 2019, 130, 664-674. [CrossRef] [PubMed]

24. Pawlaczyk-Graja, I. Polyphenolic-polysaccharide conjugates from flowers and fruits of single-seeded hawthorn (Crataegus monogyna Jacq.): Chemical profiles and mechanisms of anticoagulant activity. Int. J. Biol. Macromol. 2018, 116, 869-879. [CrossRef] [PubMed]

25. Ho, T.C.; Kiddane, A.T.; Sivagnanam, S.P.; Park, J.-S.; Cho, Y.-J.; Getachew, A.T.; Nguyen, T.-T.T.; Kim, G.-D.; Chun, B.-S. Green extraction of polyphenolic-polysaccharide conjugates from Pseuderanthemum palatiferum (Nees) Radlk.: Chemical profile and anticoagulant activity. Int. J. Biol. Macromol. 2020, 157, 484-493. [CrossRef] [PubMed]

26. Wu, D.T.; Liu, W.; Xian, M.L.; Du, G.; Liu, X.; He, J.J.; Wang, P.; Qin, W.; Zhao, L. Polyphenolic-Protein-Polysaccharide Complexes from Hovenia dulcis: Insights into Extraction Methods on Their Physicochemical Properties and In Vitro Bioactivities. Foods 2020, 9, 456. [CrossRef]

27. Singleton, V.L.; Rossi, J.A. Colorimetry of Total Phenolics with Phosphomolybdic-Phosphotungstic Acid Reagents. Am. J. Enol. Vitic. 1965, 16, 144-158.

28. Bradford, M.M. A rapid and sensitive method for the quantitation of microgram quantities of protein utilizing the principle of protein-dye binding. Anal. Biochem. 1976, 72, 248-254. [CrossRef]

29. Podolec, P.; Szabó, A.H.; Blaško, J.; Kubinec, R.; Górová, R.; Višňovský, J.; Gnipová, A.; Horváth, A.; Bierhanzl, V.; Hložek, T.; et al. Direct silylation of Trypanosoma brucei metabolites in aqueous samples and their GC-MS/MS analysis. J. Chromatogr. B 2014, 967, 134-138. [CrossRef]

30. Selvendran, R.R.; March, J.F.; Ring, S.G. Determination of aldoses and uronic acid content of vegetable fiber. Anal. Biochem. 1979, 96, 282-292. [CrossRef]

31. Blumenkrantz, N.; Asboe-Hansen, G. New method for quantitative determination of uronic acids. Anal. Biochem. 1973, 54, 484-489. [CrossRef]

32. Giusti, M.M.; Wrolstad, R.E. Characterization and Measurement of Anthocyanins by UV-Visible Spectroscopy. In Current Protocols in Food Analytical Chemistry; John Wiley \& Sons, Inc.: New York, NY, USA, 2001.

33. Correia, P.; Araújo, P.; Ribeiro, C.; Oliveira, H.; Pereira, A.R.; Mateus, N.; de Freitas, V.; Brás, N.F.; Gameiro, P.; Coelho, P.; et al. Anthocyanin-Related Pigments: Natural Allies for Skin Health Maintenance and Protection. Antioxidants 2021, 10, 1038. [CrossRef] [PubMed] 
34. Yang, P.; Li, H.; Wang, H.; Han, F.; Jing, S.; Yuan, C.; Guo, A.; Zhang, Y.; Xu, Z. Dispersive Liquid-Liquid Microextraction Method for HPLC Determination of Phenolic Compounds in Wine. Food Anal. Methods 2017, 10, 2383-2397. [CrossRef]

35. Azevedo, J.; Fernandes, A.; Oliveira, J.; Brás, N.F.; Reis, S.F.; Lopes, P.; Roseira, I.; Cabral, M.; Mateus, N.; de Freitas, V. Reactivity of Cork Extracts with (+)-Catechin and Malvidin-3-O-glucoside in Wine Model Solutions: Identification of a New Family of Ellagitannin-Derived Compounds (Corklins). J. Agric. Food Chem. 2017, 65, 8714-8726. [CrossRef] [PubMed]

36. Teixeira, N.; Mateus, N.; de Freitas, V.; Oliveira, J. Wine industry by-product: Full polyphenolic characterization of grape stalks. Food Chem. 2018, 268, 110-117. [CrossRef] [PubMed]

37. Oliveira, J.; da Silva, M.A.; Parola, J.A.; Mateus, N.; Brás, N.F.; Ramos, M.J.; de Freitas, V. Structural characterization of a A-type linked trimeric anthocyanin derived pigment occurring in a young Port wine. Food Chem. 2013, 141, 1987-1996. [CrossRef] [PubMed]

38. Ross, K.A.; Beta, T.; Arntfield, S.D. A comparative study on the phenolic acids identified and quantified in dry beans using HPLC as affected by different extraction and hydrolysis methods. Food Chem. 2009, 113, 336-344. [CrossRef]

39. Fernandes, P.A.R.; Silva, A.M.S.; Evtuguin, D.V.; Nunes, F.M.; Wessel, D.F.; Cardoso, S.M.; Coimbra, M.A. The hydrophobic polysaccharides of apple pomace. Carbohydr. Polym. 2019, 223, 115132. [CrossRef] [PubMed]

40. Coelho, C.; Ribeiro, M.; Cruz, A.C.; Domingues, M.R.; Coimbra, M.A.; Bunzel, M.; Nunes, F.M. Nature of phenolic compounds in coffee melanoidins. J. Agric. Food Chem. 2014, 62, 7843-7853. [CrossRef] [PubMed]

41. Benzie, I.F.F.; Strain, J.J. The Ferric Reducing Ability of Plasma (FRAP) as a Measure of "Antioxidant Power": The FRAP Assay. Anal. Biochem. 1996, 239, 70-76. [CrossRef] [PubMed]

42. Bondet, V.; Brand-Williams, W.; Berset, C. Kinetics and Mechanisms of Antioxidant Activity using the DPPH. Free Radical Method. Lebensm. Wiss. Und-Technol. 1997, 30, 609-615. [CrossRef]

43. Van de Laar, F.A.; Lucassen, P.L.; Akkermans, R.P.; van de Lisdonk, E.H.; Rutten, G.E.; van Weel, C. $\alpha$-Glucosidase Inhibitors for Patients With Type 2 Diabetes. Results A Cochrane Syst. Rev. Meta-Anal. 2005, 28, 154-163. [CrossRef]

44. Liu, W.; Li, F.; Wang, P.; Liu, X.; He, J.-J.; Xian, M.-L.; Zhao, L.; Qin, W.; Gan, R.-Y.; Wu, D.-T. Effects of drying methods on the physicochemical characteristics and bioactivities of polyphenolic-protein-polysaccharide conjugates from Hovenia dulcis. Int. J. Biol. Macromol. 2020, 148, 1211-1221. [CrossRef] [PubMed]

45. Han, F.; Oliveira, H.; Brás, N.F.; Fernandes, I.; Cruz, L.; De Freitas, V.; Mateus, N. In vitro gastrointestinal absorption of red wine anthocyanins_-Impact of structural complexity and phase II metabolization. Food Chem. 2020, 317, 126398. [CrossRef] [PubMed]

46. Santbergen, M.J.C.; van der Zande, M.; Gerssen, A.; Bouwmeester, H.; Nielen, M.W.F. Dynamic in vitro intestinal barrier model coupled to chip-based liquid chromatography mass spectrometry for oral bioavailability studies. Anal. Bioanal. Chem. 2020, 412, 1111-1122. [CrossRef] [PubMed]

47. Pérez-Ramírez, I.F.; Reynoso-Camacho, R.; Saura-Calixto, F.; Pérez-Jiménez, J. Comprehensive Characterization of Extractable and Nonextractable Phenolic Compounds by High-Performance Liquid Chromatography-Electrospray Ionization-Quadrupole Time-of-Flight of a Grape/Pomegranate Pomace Dietary Supplement. J. Agric. Food Chem. 2018, 66, 661-673. [CrossRef] [PubMed]

48. Gao, L.; Girard, B.; Mazza, G.; Reynolds, A.G. Changes in Anthocyanins and Color Characteristics of Pinot Noir Wines during Different Vinification Processes. J. Agric. Food Chem. 1997, 45, 2003-2008. [CrossRef]

49. Jing, P.; Giusti, M.M. Characterization of Anthocyanin-Rich Waste from Purple Corncobs (Zea mays L.) and Its Application to Color Milk. J. Agric. Food Chem. 2005, 53, 8775-8781. [CrossRef] [PubMed]

50. Teixeira, N.; Azevedo, J.; Mateus, N.; de Freitas, V. Proanthocyanidin screening by LC-ESI-MS of Portuguese red wines made with teinturier grapes. Food Chem. 2016, 190, 300-307. [CrossRef]

51. Saéz, V.; Riquelme, S.; Baer, D.V.; Vallverdú-Queralt, A. Phenolic Profile of Grape Canes: Novel Compounds Identified by LC-ESI-LTQ-Orbitrap-MS. Molecules 2019, 24, 3763. [CrossRef] [PubMed]

52. He, L.; Yan, X.; Liang, J.; Li, S.; He, H.; Xiong, Q.; Lai, X.; Hou, S.; Huang, S. Comparison of different extraction methods for polysaccharides from Dendrobium officinale stem. Carbohydr. Polym. 2018, 198, 101-108. [CrossRef]

53. Spinei, M.; Oroian, M. The Potential of Grape Pomace Varieties as a Dietary Source of Pectic Substances. Foods 2021, $10,867$. [CrossRef]

54. Hernández-Hierro, J.M.; Quijada-Morín, N.; Martínez-Lapuente, L.; Guadalupe, Z.; Ayestarán, B.; Rivas-Gonzalo, J.C.; EscribanoBailón, M.T. Relationship between skin cell wall composition and anthocyanin extractability of Vitis vinifera L. cv. Tempranillo at different grape ripeness degree. Food Chem. 2014, 146, 41-47. [CrossRef] [PubMed]

55. Vidal, S.; Williams, P.; O’Neill, M.A.; Pellerin, P. Polysaccharides from grape berry cell walls. Part I: Tissue distribution and structural characterization of the pectic polysaccharides. Carbohydr. Polym. 2001, 45, 315-323. [CrossRef]

56. Fernandes, P.A.R.; Le Bourvellec, C.; Renard, C.M.G.C.; Nunes, F.M.; Bastos, R.; Coelho, E.; Wessel, D.F.; Coimbra, M.A.; Cardoso, S.M. Revisiting the chemistry of apple pomace polyphenols. Food Chem. 2019, 294, 9-18. [CrossRef] [PubMed]

57. Le Bourvellec, C.; Guyot, S.; Renard, C.M.G.C. Non-covalent interaction between procyanidins and apple cell wall material: Part I. Effect of some environmental parameters. Biochim. Biophys. Acta (BBA)Gen. Subj. 2004, 1672, 192-202. [CrossRef]

58. Tsirigotis-Maniecka, M.; Pawlaczyk-Graja, I.; Ziewiecki, R.; Balicki, S.; Matulová, M.; Capek, P.; Czechowski, F.; Gancarz, R. The polyphenolic-polysaccharide complex of Agrimonia eupatoria L. as an indirect thrombin inhibitor-isolation and chemical characterization. Int. J. Biol. Macromol. 2019, 125, 124-132. [CrossRef] [PubMed]

59. Jiménez, J.P.; Serrano, J.; Tabernero, M.; Arranz, S.; Díaz-Rubio, M.E.; García-Diz, L.; Goñi, I.; Saura-Calixto, F. Effects of grape antioxidant dietary fiber in cardiovascular disease risk factors. Nutrition 2008, 24, 646-653. [CrossRef] [PubMed] 
60. Gong, L.; Feng, D.; Wang, T.; Ren, Y.; Liu, Y.; Wang, J. Inhibitors of $\alpha$-amylase and $\alpha$-glucosidase: Potential linkage for whole cereal foods on prevention of hyperglycemia. Food Sci. Nutr. 2020, 8, 6320-6337. [CrossRef] [PubMed]

61. Zhou, P.; Zhang, L.; Li, W.; Zhang, S.; Luo, L.; Wang, J.; Sun, B. In vitro evaluation of the anti-digestion and antioxidant effects of grape seed procyanidins according to their degrees of polymerization. J. Funct. Foods 2018, 49, 85-95. [CrossRef]

62. Rasouli, H.; Hosseini-Ghazvini, S.M.; Adibi, H.; Khodarahmi, R. Differential $\alpha$-amylase/ $\alpha$-glucosidase inhibitory activities of plant-derived phenolic compounds: A virtual screening perspective for the treatment of obesity and diabetes. Food Funct. 2017, 8, 1942-1954. [CrossRef] [PubMed]

63. Anwar, S.; Khan, S.; Almatroudi, A.; Khan, A.A.; Alsahli, M.A.; Almatroodi, S.A.; Rahmani, A.H. A review on mechanism of inhibition of advanced glycation end products formation by plant derived polyphenolic compounds. Mol. Biol. Rep. 2021, 48, 787-805. [CrossRef]

64. Song, Q.; Liu, J.; Dong, L.; Wang, X.; Zhang, X. Novel advances in inhibiting advanced glycation end product formation using natural compounds. Biomed. Pharmacother. 2021, 140, 111750. [CrossRef] [PubMed]

65. Cai, H.; Yang, X.; Cai, Q.; Ren, B.; Qiu, H.; Yao, Z. Lycium barbarum L. Polysaccharide (LBP) Reduces Glucose Uptake via Down-Regulation of SGLT-1 in Caco2 Cell. Molecules 2017, 22, 341. [CrossRef] [PubMed]

66. Faria, A.; Pestana, D.; Azevedo, J.; Martel, F.; de Freitas, V.; Azevedo, I.; Mateus, N.; Calhau, C. Absorption of anthocyanins through intestinal epithelial cells-Putative involvement of GLUT2. Mol. Nutr. Food Res. 2009, 53, 1430-1437. [CrossRef] [PubMed]

67. Johnston, K.; Sharp, P.; Clifford, M.; Morgan, L. Dietary polyphenols decrease glucose uptake by human intestinal Caco-2 cells FEBS Lett. 2005, 579, 1653-1657. [CrossRef] [PubMed]

68. Matsushita, H.; Kobayashi, M.; Tsukiyama, R.-I.; Fujimoto, M.; Suzuki, M.; Tsuji, K.; Yamamoto, K. Stimulatory effect of Shoyu polysaccharides from soy sauce on the intestinal immune system. Int. J. Mol. Med. 2008, 22, 243-247. [CrossRef] [PubMed] 